\title{
Involving the Elderly in the Design Process
}

\section{O. Demirbilek ${ }^{A \dagger}$ (Saritabak), H. Demirkan ${ }^{B}$}

Based on the concept of 'aging in place', a prescriptive model is proposed, aiming at the creation of a usable, safe and attractive built environment where the elderly residents are actively involved in the design process through collaboration sessions. Quality Function Deployment (QFD) bas been adapted to develop an evaluation and translation metbod for the collected data of the elderly end-users.

\section{Introduction}

Many studies were conducted in attempts to design better houses and interiors for the elderly ( 1 to 14). However the opinion of the elderly themselves related to the design itself is never or rarely considered, as Cavanagh (3) who involves older women in the design of house interiors and equipment in her studies mentions. The ideas and comments of old people certainly play an important role in the building design process. Woudhuysen (15) says that elderly people, besides responding to questionnaires and attending to focus groups, should also work in reams with designers, entering early and directly into the design process. This paper describes a prescripcive model in which the end users, mainly the elderly residents, can be involved actively in the design process. Quality Function Deployment (QFD) has been adapted to develop an evaluation method for the collected data (views and ideas) of the elderly end- user.

\section{The Aging Process and the Built Environment}

While getting old, one gradually looses a lot of abilities in daily life activities. Heikkinen and his colleagues (16) add that aging is associated

Middle East Technical University, Faculty of Architecture, Department of Industrial Design, 06531 lnönü Bulvari, Ankara - Turkey. e.mail:ovademir@vituvius.arch.metu.edu.tr

"Bilkent Lniversity, Faculn' of Ar, Design and Architecture, Deparment of Interior Architecture and Environmental Design, 06533, Bilkent, Ankara - Turkey e.mail: demirkan@bilkent.edu.rr

'Correspending author with an increasing prevalence of many chronic diseases and disabilities. This situation influences how old people deal with their environment. They may have problems in moving around (mobility deficits), in manipulating objects (deficits in dexterity), and in receiving proper information from outside (sensory deficits). Each of the above stated groups include a wide range of related problems. The greatest problem that an oider person faces is the loss of independence. This can be achieved by the assessment of functional status and preventing disability.

Functional status in aging includes basic activities of daily living-like feeding, dressing, ambulating, bathing, transferring from bed to toilet, grooming, and ability to communicate. Barbaccia (17) claims that problems occurring frequently are with bathing; problems with dressing, eating, and grooming are less frequent. Furhermore, he states that around $80 \%$ of the elderly people are mobile and able to get around in their home and with some limits in the community. Assistance is most often required with daily activities $(18,19,20,21)$.

Musculoskeletal dimensions, mechanical performance, nexibility of joints, muscle strength, gait speed, bone density are all important factors in the physiological system and changes occur in these with aging. Arthritis, heart disease, diabetes, difficulty with vision and hearing are more common in older people. These problems with muscles and joints as hip fractures really contribute to a decrease in activities of daily living and instrumental accivities of daily living (17). The individuals have the greatest difficultry related to most functional mobility as heavy housework; climbing stairs, walking half a mile and gripping with the upper extremities. The instrumental activities like shopping, doing light housework, and cooking are less difficult. 
A more significant cause of injury and concern are falls, which account for many hospital admissions and movement in nursing homes. They are extremely common healch problems for the elderly resulting from neuromuscular and functional decline. Nevitt (22) claims that there is little research or data to support the hypothesis that environmental modifications can prevent falls. Most of the research has been done on Caucasian population because falls are a major cause of fractures in this race and people living in Turkey belongs to a subgroup of Caucasoid. Stairways without railings, high and irregular steps, clutter on the floor, a loose rug or a bathroom without grab bars are the mostly encountered risk factors in a house.

Even ifhearing and vision deficits associated with aging can be corrected with aids, "designers should ensure that features such as door frames, door handles, steps, stairs and walkways are well-distinguished by using visual contrast, achieved either through brightness or colour differences to make the key features more conspicuous" (23). Glare from luminaries, windows and shiny surfaces should be controlled in a house environment. Local adjustable task lighting can be used to meet the special needs of eiderly people.

Kose (24) accuses architects and designers of not yer being prepared to accept design requirements for elderly people. He lists those requirements as follows: Elimination of level differences (including the elimination of door sills); installation of handrails (said by architects to interrupt design consistencies in the space); installation of door level handles; installation of larger switches; installation of easily operable facilities, etc. (25). There are certainly many other requirements that can be added to this list, such as the provision of: adequate lighting avoiding large contrasts (26), illuminated and well located light switches, visual as well as auditory alarm systems, differentiation of wall and floor surface textures, colour coding, induction loops to assist hearing aids, sound insulation, rounded comers and edges, sliding doors (particularly for cabinet and cupboard doors), contrasting stripes on the edges of the treads of any stairs, handrails extended beyond the top and the bottom of stairs, etc.

The rates of population growth and population aging vary across countries. The rate of population growth is higher in developing countries like Turkey, whereas population aging is higher in developed countries. Even if so, it is predicted that $9.3 \%$ of the population of Turkey will be over the age of 65 in the year of 2025 (27). For this reason the housing policies of Turkey should supply the housing needs of elderly people and the architects should be concerned about the quality of life of the residents at all ages.

Sandhu (28) says that the elderly are potentially the fastest growing consumer market in the developed countries. He also advises that designers and manufacturers should make evaluative research with respective groups of elderly users, at all the stages of the design process, and particularly before the introduction of new products. Brink (27) points out that most dwellings are not "senior-friendly" or barrier free, and that those dwellings are designed without considering even the basic requirements of elderly residents, resulting in their exclusion from everyday life.

While modern housing is achieving ever-greater technical capacity to meet the more specific requirements for habitability, concern for housing conditions that supports the psychological and social well-being has not followed these developments. Many studies of the elderly have attempted to enumerate and describe the typical activities performed by this age group, in the course of their days $(8,17,18,19,20,29)$. Unfortunately it has been difficult to translate this information into design applications.

It is argued by some researchers $(30,31)$ that when products and environments are made more accessible to people with limitations, they have potential benefits, for everybody, such as: lower fatigue, increase speed in performance, and lower error rates. As space requirements are more complex for the aged persons, Kose and his colleagues (2) claim that the elderly should be accepted as the derermining factor in design, and taken as a base and a reference to the human interaction with the built environment. Thus, if a house is designed (interior, fumiture and equipment) according to the requirements of elderly people, this same house will also be adequate for other age groups. This is reinforced by the words of Lee Fisher: "If the home is designed correctly, many people probably would be unaware of most of the special features for handicapped persons" (T).

\section{A Universal Design Base}

Researches have shown that psychological well-being is one of the most intrinsic aspects of successful aging $(29,32,33)$. Studies have identified various factors having impacts on the psychological well-being of the elderly including housing and neighborhood environments. Imamoglu and Imamoglu $(6,34)$ noted that, the Turkish elderly, on the whole, consider the personal (home-related) and environmental aspects of their neighborhoods most important; followed by the functional and natural characteristics; whereas, the architectural and recreational aspects are considered least important among the other qualities regarded. They also found that although the attitudes of the Turkish elderly, in general, are negative towards institurional living, they become more favorable with urbanization and age.

The current life situations of the elderly in Turkey show that they do not live in extended families. However, the Turkish culture is based on closeknit interpersonal relationships where support and sacrifice of parents toward their children, and the obedience to and responsibility of children to care for their parents in old-age are widely accepted strong values (34, 35). Thus, the housing units for the elderly should be organized in such a way to satisfy the needs for such social interdependencies. The universal design concept helps to integrate aging which is a natural stage of life into the social and physical aspects of living environments in a meaningful manner (36) without extra costs nor alterations in terms of aesthetics.

Calmenson (37) states four criteria, named as "the four A's" of universal design, as follows: accessibility, adaptability, aesthetics, and affordability. Accessibility enables a person to fully utilize the entire space, whether they have failed vision, are pregnant or use a wheelchair. Adaptability is important especially when the current or future residents plan to live in a house for many years, thereby 'aging in place'. Aesthetics refers not only to making a universally designed environment beautiful, but also to making it helpful without appearing different or urilitarian. Affordability promotes an idea that an adaptable home can be built for the same cost if it is properly designed at the beginning.

The concept of universal design relates people with their biological and cultural heritage, and it helps to define a person's sense of self, and place in the world, also connecting them to the future. People need the opportunity to shape situations, places, and activities that affect their lives. It is desirable to allow more and more aged people to get old in their present place of residence, and the universal design concept is a recent 
development to make this possible. In this concept, children, young people, aged people and disabled people are all equally considered, and there is no principal user (people with disabilities, elderty, children, pregnant women, people carrying packages, etc.) (38). According to Brink (27) universal design is usually a synonym for good design, because attention is paid to achieving the best use of space while enhancing usability; and on the other hand, it reduces costs over the long term. Furthermore, Morini and Pomposini (39) point our the social and psychological disadvantages of designing dwellings especially for the elderly, where they feel themselves rejected from everyday life. Dagostino (40) adds that universal design allows people to be independent, safe and comfortable. According to Steinfeld (21) universally designed buildings are accessible and usable by everyone, including the disabled; and they provide accommodation for the elderly and the young people, in shor, for a majority of persons. Universal design differs from accessible design which often has a medical or institutional look (21). It allows high standards of aesthetics because it is integrated in the design process from the beginning, and because it can be incorporated in any style or setting.

\section{Basic Functions of a House}

Housing must fulfill the needs for the daily activities of the elderly, and more precisely it must give them: satisfaction, security, comfort, and independence, or at least one of them. The basic functions that a house interior has to fulfill have been stated and grouped in Figure 1.
Ease in mobility includes all the movements (with their degree of easiness) that a resident can make while circulating in the house. Independence includes the feeling of it and the ability to carry out the daily life activities without assistance. Privacy, security and safety are interrelared. They deal with available systems and designs preventing and helping in rescue during any harm from outside the house (burglar, intrusion, aggression ...) or from any accident (fire, gas infiltration, smoke ...) that may occur. Safety also includes the safe use of any house equipment without the risk of accident. Privacy is also a condition reached in a state of independence, in this chart, it belongs to the safety group. A well designed house will ensure greater use, safery, security, and privacy. Shelter is the place where all the functions and activities of a house are encompassed. Aestheric includes taste, preferences and value judgments of the residents.

Researches in literature are mostly oriented toward the construction of housing for the elderly. These types of housing include: senior housing, sheltered housing, nursing houses, community dwellings, and so on. Few studies are interested in letring people aging in place $(1,41,42,43)$, without having to move. It has been pointed out that daily life activities can becarried out nearly successfuily by elderly residents with diminished abilities if they are familiar with the surrounding. On the contrary, these activities can be very hard to carry out, even by less disabled elderly people, when they are nor familiar with the surrounding $(44,45)$. In most of the studies on elderly and their house environment, their opinion and

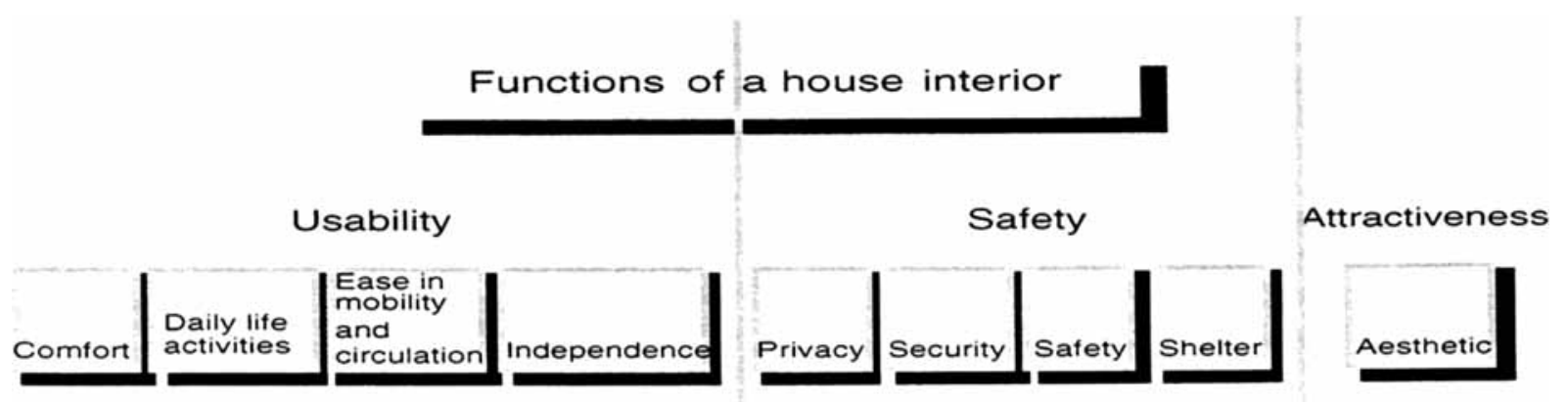

Figure 1. Basic Functions of a House

The resulting figure depicts the three main groups as usability, safery and attractiveness; which are emphasized throughout the study. Comfort, daily life activities, ease of mobility, and independence are listed under the group of usability. Shelter, security, safery, and privacy are listed under the group of safety. Aestherics belongs to the group of attractiveness. Comfort includes the feeling of thermal comfort (temperature, humidity, drafts), adequate lighting level and colour vision comfort, hearing confort, and physical comfort. Daily life activities include: cooking and eating; sleeping and resting; grooming; dressing and undressing; use of shower, bath, toilet, and wash basin; operating doors and windows; washing clorhes - washing dishes; carrying objects - moving furniture; operating thermostat; walking on carpet; reaching for high objects; chair comfort (sitting, standing up); counter convenience - (storage); stair and ramp use - elevator operation; finger and manual tasks (sewing, writing, playing cards); getting in and out of bed; hearing and viewing things; using household appliances (vacuum, iron, kitchen robor); performing hobbies (plants, knitting, needlework...); watching TV, listening to radio, hi-fi, recorders; wheel chair mobility; operating a telephone (accessibility, convenience); etc. (19) ideas during the stages of the design process were never asked. Therefore, it will be an imporant issue to provide a collaboration between elderly residents and designers.

This study proposes a collaboration berween experts and end users at the various stages of the design process. The main focus in the present study remains oriented towards a design process that will make possible the design of usable, functional, attractive, and safe interior environments (on a universal design basis) allowing to 'age in place', taking into account the real world needs of the end user (the elderly in this case) by their participation in the design process, and combining theirs with the empirical knowiedge of designers. Kose (24) points out the importance of design modifications, from the view point of usability and safety, to cope with the decreasing capability of the aging population.

The results obtained from these collaboration sessions form a base for designing appropriate house interiors and also serve as guidelines. Briefly, the creation of a physical interior environment, having in mind the notion of aging in place, is a complex task. It requires the organization of appropriate information. The knowledge of designers combined with the 
knowledge (opinions, ideas) of the elderly end users should be involved in the design process because it is not an autonomous business. Furthermore, Sheehan (46) adds that the physical design of housing interiors plays a major role in influencing the quality of life of all elderly residents.

\section{The Model}

The phases of the design process in the Usability, Safety, and Attractiveness Collaboration (USAC) Model (see Figure 2.) is as follows:

- In the first stage, collaboration sessions are organized with small groups of elderly people. Small groups consisting of 6 people are said to successfully produce up to 150 ideas in half an hour at their first attempt (47). At this stage, they will produce ideas and define their exact needs and preferences towards the design of house interiors. This will be a combination of brain storming and unstructured interviews, where the ideas, comments (written, oral, sketched, or gestures), and needs are collected. All the data collected in this stage are classified in the USAC Model.

- The second stage is the feasibility study where optimal ways to solve the problem are searched for by the designers.

- The third stage consists of the proposition of different solutions to the problem (designing house interior allowing 'aging in place'). In this stage, elderly users will be involved for the second time to make preferences among the solutions.

- The fourth stage consists of further developments and refinements of the chosen solution, detailed design, comprising all the technical side of the design process, achieved by the designers.

- The fifth stage is the construction planning.

- The sixth stage is the realization of the construction.

In this model, the end-users, mainly the elderly residents, are involved actively in the design process. The expertise of archirects and incerior designers are combined and compared with that of elderly people thenselves (their own opinions and ideas on their requirements), and related to how an interior house environment should be designed to allow aging in place'. Eason (48) sees such an approach as a combination of $d e$ sign by the user and design for the user. This combination is importantbecause human beings are not just task performers; they have ambitions, beliefs, emotions, values, satisfactions and dissatisfactions (48) of their own that no designer can anticipate or imagine for them. Furthermore, Means (41) points out that constructive dialogue and partnership between users and professionals help in improving the effective use of existing resources, in order to ensure independent living for the elderly.

\section{Methodology}

Figure 3. depicts the simplified process of this involvement and the steps to be followed.

The collaboration sessions are held with the end-users, a selected group of elderly people, male and female above 65, from the city of Ankara. Random sampling is used among a group of volunteers. In these semi structured interview sessions, a group of 4 to 6 end-users are asked to 'design' the house that they want to age in, considering all their possible requirements, needs, particular wishes and ideas. These collaboration sessions are recorded on video for later evaluation (to recall all the details).

In this collaboration, the expertise of designers and the opinions of elderly are related to the design of a house environment, interior, and/or

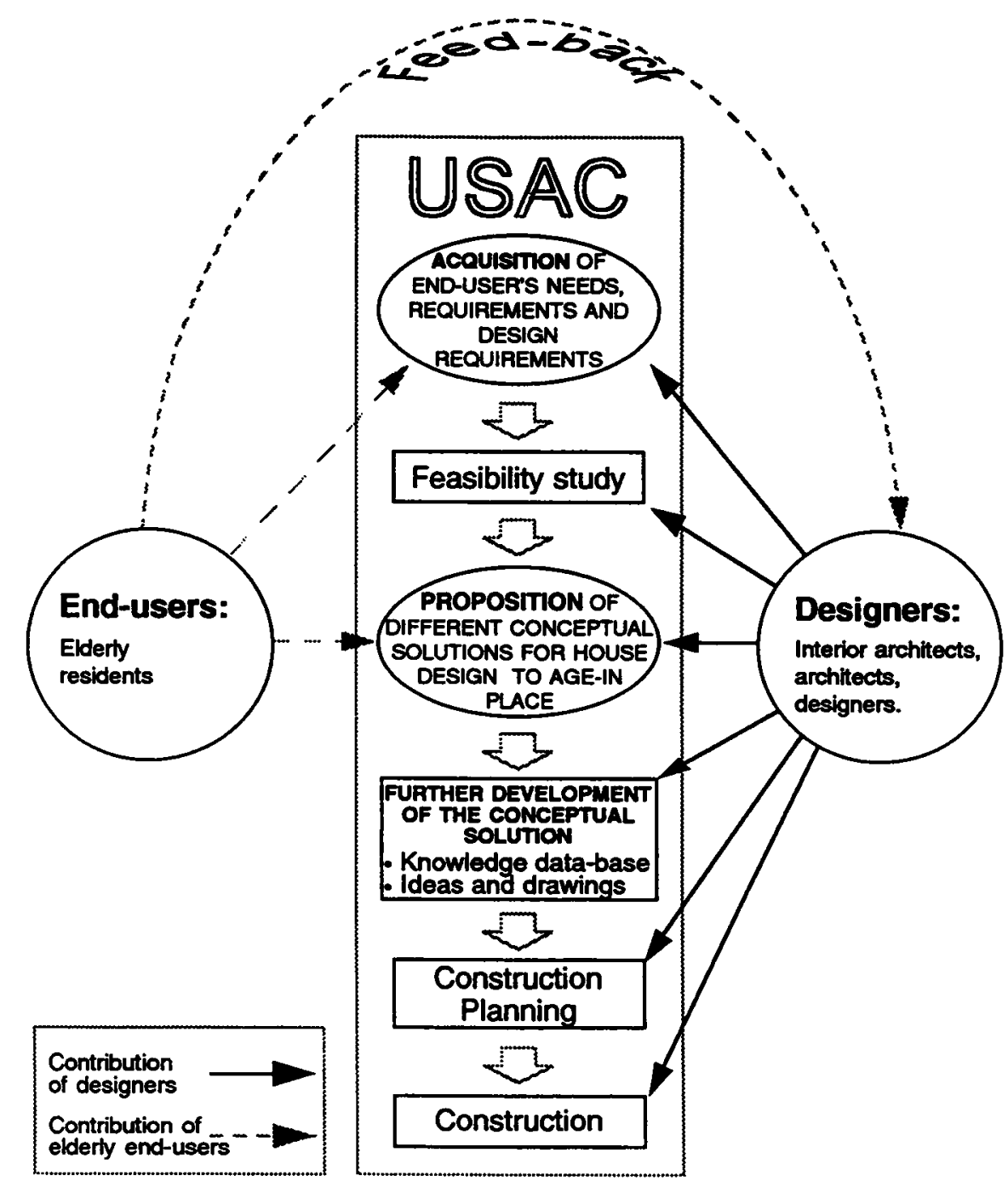

Figure 2. The USAC Model 


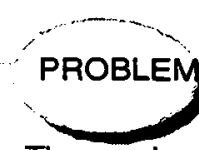

- The number of elderly increases constantly;

- Houses are not adequate to AGE-IN-PLACE;

- Designers are reticent to accept some

requirements of the elderly;

- Designers decide for the elderly.

(2) There is a mismatch between house interiors and the elderly residents

WHAT TO

DO

Ask the elderly residents (end-users):

- How they prefer to use interior spaces;

- What are their real needs and requirements.

(0) Let the end-users participate and collaborate to the various phases of the design process.

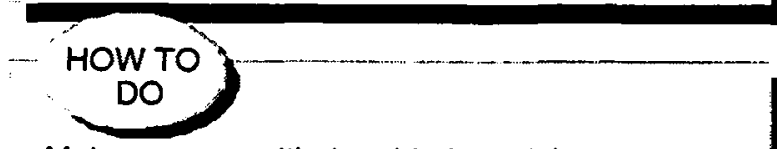

- Make surveys with the elderly and the designers;

- Organize collaboration sessions with the elderly where they are "designers";

- Collect every idea and requirement using a Usability, Safety, and Attractiveness (USAC)

Collaboration Model;

- Deploy the results to the whole design process.

(2) Collaborate with the elderly through the whole design process.

Figure 3. Involvement Process in the USAC Model

equipment to allow aging in place. In these sessions, to take place naturally, the following general conditions are taken into account for communication and coordination:

- Specific orconcrere goals of collaboration are not known to, or cannot be clearly defined by any paricipant at the outset.

- Heterogeneous systems of representation and action employed by individual menbers are necessarily involved, such as: talking, writing, skerching, moving hands, mimicking (which makes the use of a video recorder essential), etc.

- No pre-defined scheduling schemes can be applied for all the sessions. The results of those collaboration sessions are conbined and compared with the help of the USAC Model.

\section{Use of Quality Function Deployment (QFD) in the Evaluation Stage}

Hudspith (49) points out that in practice, users rarely respond in usable design terms, and that their responses are difficult to translate into dimensions. Elderly residents and designers may speak aimost a different language than that of a designer. As an example, a resident might say "I want a door that is easy to open". The translation into technical language might be "door will open with minimum applied force". Or a requirement such as "the soap should leave my skin feeling soft" must be translated into "pH or hardness specifications for the soap" (50).

QFD, which originared in Japan (devised by Professor Yoji Akao in 1972) in the 70's and was useful in the USA in the 80's, is widely applied in the business world. Today, it is one of the most appropriate methods in use that can enable designers to translate end-user needs into product requirements, because it focuses on quality as going beyond an "us-versus-them" mentality ( 51 ). In this study, the processes of QFD are adapted and modified into the USAC Model to develop an evaluation method for the collected views and ideas of the elderly end-users, on their design ideas, level of interest, needs and preferences related to the design of their house interior. In this method, the users (the elderly residents) are seen as designers or members of the design team, and they are cooperating in the design process. This method fits the abilities and circumstances of all the people involved, asking them to help in the design of the research itself as well as contributing to its results.

\section{Conclusion}

To avoid complicating the lives of elderly people by imposing on them inadequate housing, their contribution in the housing design process should be encouraged (3). What people's different needs are; how they might prefer to use interior house spaces; what their housing requirements are; and what their opinions and ideas are, should be questioned before starting the design process and during this process. According to Eason (48), in such a design process, the end users can influence the design in a way that agrees with their goals and beliefs because "only those who will be affected can decide what is in their best interest" (p. 1668). Furthermore, Mitchell (52) argues that the design theories of architects such as Le Corbusier and Venturi were essentially incomplete because they were only dealing with forms, with no meaningful attention paid on how the users will be affected by these forms. To be able to design high-quality housing where people will want to live and age-in-place, professionals should have the direct contribution of elderly people's lifestyles and requirements (3). The main goal of such a collaboration is to improve the quality of life of elderly residents in particular, preserving their dignity, independence and self-determination, and to improve the quality of life of all residents in general. This study can also be extended to areas other than the private house interior environment, such as public areas, offices, schools, hotels, hospitals.

\section{References}

1 S. KOSE:Aging in Place: Importance of Universal Design Concept in HousingPolicy.e-mailonISARC43Conference,skose@keken.go.jp, 11 Auguss 1996

2 S.KOSE,J.CHRISTOPHERSEN, A D' INNOCENZO, R. D' INNOCENZO, G. HALLBERG, E. JUILLET, D. KITTANG, G. WEBBER and N. WOETMAN: Design for All Ages. Report of CIB/TG19 Stockbolm Meeting, Royal mstitute of Tecbnology, Stockholm, 28-29 May 1996.

3 S.CAVANAGH: The Space We Need: Principles of Housing Design for Older Women, Women with Children, and Parents with Disabilities. 
In E. Komut (ed.). Housing Questions of the 'Others'. Chamber of Architects of Turkey, Ankara, 1996. pp. 67.76.

4 H. VIROKANNAS, S. VÄYRYNEN, T. LEINONEN, K. KOSKI, KIRVESOJA, M. ALATALO, M.L. KEMPPAINEN, P. MIELONEN and M. H. PIRINEN: Gerontological Progress for Better Indoor Mobility in the Elderly. Proceedings of the $I^{4}$ International Conference on Applied Ergonomics ICAE' 96, Istanbul, 21-24 May 1996. pp. 720-723.

5 J.BERNSEN,A. FL ØE andS.SCHENSTR ØM:Age:No Problem. Danish Design Centre, København, 1994.

6 V.IMAMOGLU, E. O. IMAMOGLU: Housing and Living Environments of the Turkish Elderly. Joumal of Environmental Psycbology, Vol. 12, 1992. pp. 35-43.

7 B. B. RASCHKO:Housing Interiors for the Disabled and Elderly. Van Nostrand Reinhold, New York, 1991.

8 T. O. BLANK: Older Persons and their Housing, Today and Tomorrow. C.C. Thomas. Springfield, Ill., S.A. 1988.

9 M.P. LAWTON, I ALTMAN, and J. F. WOHLWLLL: Elderly People and the Environment. Plenum Press, New York, 1984.

10 V. M. FALETI: Human Factors Research and Functional Environments. Elderly People and the Environment. Lawton, M. P., Aitman, I. and Wohlwill, J. F. (eds.). Plenum Press, New York, 1984.

11 V. REGNIER, and T. O.BYERTS: Applying Research to Plan and Design of Housing for the Elderly. Housing for a Maturing Population. In Steward, N. (ed). Urban Land Institute, Washington, 1983.

12 S. C. HOWELL: Designing for Ageing: Patterns of Use. The MIT Press, Cambridge, 1980.

13 F. H. ROHLES: Problems of Habitability of the Elderly in Public Housing, Proceedings of the Eleventh Annual Research Conference of the American Institute of Arcbitects on 'Designing for the Elderly', Vanderbilt University, 1976.

14 L.A. PASTALAN:The Simulation of Age Related Sensory Losses: ANew Approacb to the Study of Environmental Barriers. University of Michigan, Ann Arbor, 1973.

15 J. A. WOUDHUYSEN: Call for Transgenerational Design. Applied Ergonomics, Vol. 24, No.1, 1993. pp. 44-46.

16 E. HEIKKINEN, W. E. WATERS, and Z. J. Brzezeñski: The Elderly in Eleven Countries, a Sociomedical Survey. World Health Organization, Copenhagen, 1983.

17 J. C. BARBACCIA: Changes in Physical Function and the Ageing Process: Implicationsfor Facility Design. In D. Driver (ed.), Proceedings of Blueprint for Aging, CA., Oakland, 1995.

18 M. C. CLARK, J.C. SARA, and R. A. WEBER: Older Adults and Daily Living Task Profiles. Human Factors, Vol. 32, No. 5, 1990. pp. 537. 549 .

19 O. DEMIRBILEK: Ageing and the Activities of Daily Living. Proceedings of the $1^{3}$ International Virtual Conference on the Internet on Ergonomics CybErg'96, September 1996 . pp. 342-348. htтp:// www.curtin.edu.au/conference/cyberg/ centre/paper/demirbilek/ paper.htlm, Perth, 1-30

20 M. P. LAWTON: Ageing and Performance of Home Tasks. Human Factor; Vol. 32, No. 5, 1990. pp. 527.536 .
21 E. STEINFELD: The Concept of Universal Design. Sixth lbero-American Conference on Accessibility. Centre for Independent Living, IDeA Publications, http://www.adaptenv.org/ -idea/publications/papers/concept_uni_des.htlm. Rio de Janeiro, June 1994.

22 M. NEVITT: Risk Factors for Falls. In D. Driver (ed.), Proceedings of Blueprint for Ageing, Oakland, CA., 1995.

23 I. BAILEY: Visual Environments of Older Adults. In D. Driver (ed.), Proceedings of Blueprint for Ageing, Oakland, CA., 1995.

24 S. KOSE: Changing Lifestyles, Changing Housing Form: Japanese Housing in Transition. In M. Bulos and N. Teymur (eds.). Housing: Design, Research, Education. Athenaeum Press, Newcastle, 1993. pp. 193-206.

25 S. KOSE, M. NAKAOHJI: Design Guidelines for Dwellings for an Ageing Sociery-A Japanese Perspective, Japanese Housing Policy for Ageing Sociery. Building Research and Information, Vol. 19, No. 1, 1991. pp. 24-30.

26 G. SALMON: Caring Environments for Frail Elderly People. In Geoffrey Salmon, (ed.) Harlow, Longman Sciendific \& Technical, Essex, 1993. pp. 8-11.

27 S. BRINK: Housing Options for Elderly People: Generic Solutions that Include or Special Solutions that Exclude?. In E. Komut (ed.). Housing Questions of the 'Otbers'. Chamber of Architects of Turkey, Ankara, 1996. pp. 347-356.

28 J. SANDHU: Design for the Elderly; User-based Evaluation Studies Involving Elderly Users With Special Needs.Applied Engonomics. Vol. 24, No.1, 1993. pp. 30-34.

29 F. M. CARP: Housing and Living Environments of Older People. In R H. Bistock and E. Shanas (eds.), Handbook of Ageing and the Social Sciences. D. Van Nostrand, New York, 1976. pp. 244-271.

30 B. R. CONNELL, M. JONES, R. MACE, J. MUELLER, A. MULUCK, E. OSTROFF, J. SANFORD, E. STEINFELD, M. STORY, and G. VANDERHEIDEN: The Principles of Universal Design. Compilation of Papers and Books, 1995. hitp://trace.wisc.edu/text/univdesn/ 30_some.hum

31 J.WOODS: Simplifying the Interface for Everyone.Applied Ergonom ics, Vol. 24, No.1, 1993. pp. 28-29.

32 M. P. LAWTON, L. NAHEMOW: Ecology and the Ageing Process: Psycbology of Adult Development and Ageing. In C. Eisdorfer and M.P. Lawton (eds.), Psychology of Adult Development and Ageing, American Psychological Association, Washington, 1973. pp. 619-674.

33 P. M. SCHWIRLAN, SCHWIRIAN: Neighboring, Residential Satisfaction and Psychological Well-being in Urban Elders. Joumal of Community Psycbology, Vol. 21, 1993. pp. 285-297.

34 V. IMAMOGLU, E. O. IMAMOGLU: Current Life Situations and Attitudes of the Turkish Elderly Towards Institutional Living. In $\mathrm{H}$. Pamir, V. Imamoglu and N. Teymur (eds.) Culture, Space and History, METU Faculty of Architecture Press, Ankara, Vol. 3, 1990. pp. 248-257.

35 Ç. KAGITÇIBASI: Intra-Family Interaction and a Model of Change. In Family in Turkish Sociery: Sociological and Legal lssues, Turkish Social Science Associations, Mava Publishing Ltd, Ankara, 1985.

36 H. DEMIRKAN: Adaptable House Design. In O. Ural, and D. Alt nbilek, and T. Bingönül (eds.). Proceedings of the XXIV tb LAHS World Housing Congress, How to House a Nation: the Challenge for 
the $X X I^{s}$ Century. Middle East Technical University, Ankara, 27-31 May 1996. pp. 19-29.

37 R. W. CALMENSON: The Practice and Hope of Susan Bebar, http:// www. isdesignet.com/SSdesigNET/Magazine/Jun'95/Cover.html, 1995.

38 E. STEINFELD, and S. DANFORT: Automated Doors: Towards Universal Design.IDeA@arch.buffalo.edu, The Centre for Inclusive Design and Environmental Access, SUNNY/Buffalo, 1993.

39 A. MORINI, and R. POMPOSINI: New Designs for Aged People Hous. ing. In O. Ural, D.Altinbilek, and T. Birgönül (eds.). XXNth LAHS World Housing Congress, 1996.

40 K. L. DAGOSTINO:Universal Design: Barrier Free Living. CAARReal Estate Weekly. http://www.caar.com/REW/Edir\%20Archives/ UniversalDesign, 1996.

41 R. MEANS: From 'Special Needs' Housing to Independent Living. Housing Studies, Vol. 11, No. 2, 1996. pp. 207-231.

42 E. E, STEINFELD, and M. S. SCOTT: Enabling Home Environments: Strategies for Aging in Place, IDEA@arch.buffalo.edu, 1996.

43 D. A HOWE: Creating Vital Communities; Planning for Our Ageing Society. Planning Commissioners Joumal, Vol. 7, December 1992.

44 M. P. LAWTON: Elderly in Context: Perspectives from Environmental Psychology and Gerontology. Environment and Bebavior, Vol. 17,
1985. pp. $501-519$.

45 P.A. PARMELEE and M. P. LAWTON: The Design of Special Environmentsfor the Aged. InJ. E. Birren and K. W. Schaie (eds.), Handbook of the Psycbology of Ageing. Academic Press, Califomia, 1990. pp. 464. 488.

46 N. W. SHEEHAN: Successful Administration of Senior Housing: Working with Elderly Residents. Sage Publications, London, 1992.

47 J. C. JONES: Design Methods, Seeds of Human Futures, WilleyInterscience, London, 1974.

48 K D. EASON: User Centered Design: For Users or by Users?. Ergonomics, Vol. 38, No. 8, 1995. 1667-1673 pp.

49 S. HUDSPITH: Utility, Ceremony and Appeal: a Framework for Considering Whole Product Function and User Experience. DRS-News, The Electronic Newsletter of the Design Research Society, Vol. 2, N.11, November 1997.

50 J. EVANS, and W. M. LINDSAY: The Management and Control of Quality. West Publishing Company, Minneapolis, 1993.

51 O. PORT, and J. CAREY: The Quality Imperative: Overview, Questing for the Best. Business Week, 2 December 1991. pp. 17-23.

52 C. T. MTTCHELL: Action, Perception, and the Realization of Design. Design Studies, Vol. 16, 1995. pp. 4-28. 